\title{
Infection control in the UK: an antimicrobial resistance perspective
}

\author{
Elecia Henry ${ }^{1}$, Robert B Smith ${ }^{2}$, Michael Collins ${ }^{3}$, Susan J Bird ${ }^{1}$, Pauline Gowland ${ }^{1}$ and John P Cassella \\ ${ }^{1}$ School of Life Sciences and Education, Staffordshire University, \\ Stoke-on-Trent, Staffordshire, ST4 2DF, United Kingdom \\ ${ }^{2}$ Chemistry, School of Physical Sciences and Computing, \\ Preston UCLan, PR1 2HE, United Kingdom \\ ${ }^{3}$ Chesterfield Royal Hospital NHS Foundation Trust, Chesterfield Road, \\ Calow, Chesterfield, Derbyshire, S44 5BL, United Kingdom \\ ${ }^{4}$ School of Law, Policing and Forensics, Staffordshire University, \\ Stoke-on-Trent, Staffordshire, ST4 2DF, United Kingdom
}

\begin{abstract}
The spread of healthcare-associated infections has become a matter of global concern. These infections, which were once solely limited to hospital settings, have emerged in the community. Reduced infection control practices strengthen this rapid spread of infections, which has led to the increase in the occurrence of multidrug resistant organisms. The state of infection control in the United Kingdom is of extreme importance because of several reported cases of infections caused by these organisms. In addition to antimicrobial usage in human medicine, antimicrobial agents used in agriculture must be considered as major factors in the prevalence of resistant organisms and the implications to the UK. However, this increased occurrence of antimicrobial resistant bacteria and their resulting infections could be reduced with the application of effective policies for antibiotic use in agricultural environments, stringent decontamination and sterilisation techniques and better regulations that encourage the search for, and development of, new and novel drugs.
\end{abstract}

Keywords: Infection control, healthcare associated infections, antimicrobial drug resistance, prophylaxis, health policy.

\section{Corresponding Author}

Elecia Henry

School of Life Sciences and Education, Staffordshire University, Stoke-on-Trent,

Staffordshire, ST4 2DF, United Kingdom.

Email: Elecia.Henry@research.staffs.ac.uk 


\section{Introduction}

With a prevalence of $6.4 \%,{ }^{1}$ the spread of healthcareassociated infections (HCAls) and their subsequent control has become an important issue in hospitals. ${ }^{2}$ Historically, the hospital setting was subjected to daily rigorous sanitisation by dedicated cleaning staff, and all medical students and staff had to observe a stringent hygiene regimen. ${ }^{3}$ Over time, there was a decrease in following these strict rules of hospital hygiene resulting in an increase in HCAls. As a result, infection control practices, although not the primary cause of disease transmission, suffered great setbacks leading to the unintended spread of infectious diseases. ${ }^{3}$

Reduction in global infection control practices has led indirectly to the development of antimicrobial resistance (AMR), which is the evolution of pathogenic microorganisms to become resistant to anti-infective agents. Occurrence of these resistant microorganisms has increased worldwide, ${ }^{4}$ spreading to the UK and increasing the risks of both patients and healthcare workers acquiring these infections in a healthcare setting as reported by the National Institute for Health and Care Excellence (NICE). ${ }^{5}$ These infections, which were once mainly hospital-acquired, are now seen in the community and the issue of increasing resistance, as reported by $\mathrm{WHO}^{6}{ }^{6}$ to antimicrobials has also become an issue beyond infection control in the hospital environment.

This paper focuses on the current state of infection control in the UK in terms of the major issues regarding anti microbial resistance. Consideration of antimicrobial usage in agriculture and human medicine will be reviewed, as well as their consequences relating to the major causes of AMR, the prevalence of global threat from this resistance and the implications to the UK. The need to develop new antibiotics as a consequence of this issue will be considered.

\section{Methods}

The methodology used for data collection was an internet search using keywords and phrases related to infection control in the UK and antibiotic use on UK farms and in UK human medicine. Other phrases used in the search were those involving causes and occurrences of AMR including the importance of new antimicrobial agents. The internet search engines used included ScienceDirect, Google Scholar, the Antimicrobial Resistance and Healthcare-associated Infections (AMRHAI) reference unit, the Department of Public Health (UK), Public Health England and the World Health Organisation (WHO).

\section{Antibiotic use on UK farms}

In a 2014 Review on Antimicrobial Resistance that was announced by the UK Prime Minister, several measures were identified to deal with the growing problem of AMR. One of these measures was a global commitment to monitor the use of antibiotic drugs by humans, in agriculture and in the environment.?

Although overlooked because of the restrictions placed on the class of antibiotics used, antimicrobial agents in livestock farming do contribute to AMR. ${ }^{8}$ These drugs are used for various reasons such as for medicinal purposes, whether by mass medication (metaphylaxis) or preventative medication (prophylaxis), and to promote growth of the animals. Although the use of antibiotics as growth aids have been banned in Europe, they are still being used as prophylactics. ${ }^{9}$

In the United Kingdom, De Briyne et al. ${ }^{10}$ reported that penicillins and tetracylines were the most commonly used antibiotics in cattle (32\% and $10 \%$ respectively) and horses ( $24 \%$ and $11 \%$ respectively) to treat disorders such as mastitis and respiratory infections. In another study involving 88 UK farms, heifer calves with respiratory diseases, e.g., pneumonia, were treated with antibiotics $(11.3 \% \pm 15.8 \%) .{ }^{11}$ Despite the availability of guidelines on antibiotic use in agriculture, $50 \%$ of farmers appear to be unfamiliar with these guidelines leading to possible inefficient farming practices. ${ }^{12}$

Commercially available antimicrobial agents, such as ivermectin, are also used on goat farms in the UK to treat ectoparasites such as lice and mange. ${ }^{13}$ Extensive use of this macrocyclic lactone and other unnamed antibiotics by many goat farmers may have been ineffectively regulated and could have contributed to the increase in antibiotic resistance of infectious ectoparasites. $^{13}$

A survey of UK broiler farms conducted by Hughes et al. ${ }^{14}$ showed that $32 \%$ of poultry farmers used prescribed antibiotics such as amoxicillin for metaphylactic 
purposes. On some participating farms, other antibiotics such as trimethoprim/sulfadiazine (16.8\%) and tylosin tartrate $(11.7 \%)$ were used as prophylactics. ${ }^{14}$ Results of the 2008 study indicated that antibiotics were mainly used to prevent diseases in broilers rather than to treat them. Antibiotic management on broiler farms needs further investigation since antibiotic misuse is a potential factor in AMR.

United Kingdom pig farmers, like some European pig farmers, ${ }^{15}$ seemed to focus more on their economic issues rather than infections in their animals ${ }^{16}$ leading to overuse of antibiotics. As a consequence, it has been shown that there is a clear connection between the poor regulation of antibiotic use in UK farms and AMR in humans. ${ }^{8}$

\section{Antibiotic use in UK human medicine}

It is without doubt that antimicrobial agents have been effective against many human infectious diseases. The incidence of infectious diseases in the UK has not notably increased but the total usage of these agents have reportedly increased by $4.1 \%$ across the NHS Trusts in a five-year period (2008-2012) ${ }^{17}$ While there has been a reduction in the use of fluoroquinolones, such as ciprofloxacin (-23.8\%), within the same period, the 2014 study showed that there was an increase in the use of other drugs such as meropenem of the carbapenem class (94.8\%), and penicillins such as piperacillin/tazobactam (142.3\%). While the report provides expected and observed data on point-ofcare antimicrobial usage, it does not show progressive usage, which is crucial in antimicrobial management.

Consequential spread of infectious diarrhoea caused by Clostridium difficile is reported to be a major concern in hospitals. In a 2015 study, ${ }_{18}^{18}$ the mean number of patients suspected to be infected with these organisms was estimated to be $149.6 \pm 173.6$ in small hospitals, $75.0 \pm 27.8$ in medium hospitals and 43.78 \pm 37.7 in large hospitals. In order to treat patients with diarrhoea that resulted from Clostridum difficile infection, metronidazole and fidaxomicin were the primary antimicrobial agents used while vancomycin was the secondary drug of choice. ${ }^{18}$ One concern that emerged from the study was that with the increasing incidence there was the possible spread of infections due to poor infection control practices. Without adequate infection control, the risk of the emergence of antimicrobial resistant Clostridium difficile increases. Since more first-line and second-line antibiotics are being used to treat infectious diarrhoea and a number of patients (mean $=10 \pm 0.0$ ) are re-admitted after an uncompleted course of treatment of the same drugs, there is the concern that AMR in Clostridium difficile could develop.

The concern of the spread of HCAls was also noted in a 2009 study by Burnett et al. ${ }^{19}$ Findings from the report that focused on patients with and without Staphylococcus aureus septicaemia identified critical issues of infection control that needed attention, such as communication, patient confidence in the NHS, and health and safety practices. Antibiotics are understandably used against HCAls but there is the need to monitor the possible spread of resistant organisms with increased use in a closed environment found in healthcare settings. Another important concern is the use of antibiotics by persons outside of the hospital environment. Antimicrobial agents are also prescribed by general practitioners in the community. A review of databases such as the Clinical Practice Research Datalink (CPRD) by Shallcross and Davies ${ }^{20}$ indicates that $80-90 \%$ of antibiotic prescriptions are given in primary care facilities. However, these programmes do not record actual use of antibiotics by patients. The possibility for the spread of resistant organisms between hospitals and community environments in conditions promoting the maintenance of resistance can be inferred.

\section{The prevalence of antimicrobial resistance}

Antimicrobial resistance is the development of reduced sensitivity to antimicrobial agents in microorganisms. Major antimicrobial resistant organisms as listed by Tang et al. ${ }^{21}$ include meticillin-resistant Staphylococcus aureus (MRSA), vancomycin-resistant enterococci (VRE), extended spectrum $\beta$-lactamase-producing (ESBL) Enterobacteriaceae, carbapenemase-producing Enterobacteriaceae (CPE) and carbapenem-resistant Acinetobacter baumannii (CRA). The main mechanisms of resistance in such organisms usually involve either the transmission of resistant genetic material from one bacterial cell to another or mutation/s in new genes. Antimicrobial resistance has become a global epidemic resulting in the generation of AMR policies 
in many regions, including Europe. The European Centre for Disease Prevention and Control (ECDC) has acknowledged the threat of AMR and has identified the major causes of the rapid spread of AMR across Europe with a particular source being the use of antibiotics in agriculture. ${ }^{22} \mathrm{~A}$ report from the B-Debate meeting with public health authorities across Europe stated that the unchecked use of antibiotics in farming practices led to selective pressure for resistant organisms, which could spread to humans. ${ }^{22}$ These resistant organisms are spread through human consumption of inadequately prepared meat products ${ }^{23}$ and dairy milk, ${ }^{24}$ and human contact with animal waste. ${ }^{25,26}$ Snow et al. ${ }^{25}$ determined that 17 of 65 sampled dairy farms received animals with various strains of CTX-M E. coli, which is an ESBL-producing microorganism. Findings of the study outlined insufficient infection control practices, such as slurry containment, open herding and inadequate cleaning of feeding equipment used for calves. ${ }^{25}$

Mismanaged antimicrobial chemotherapy in relation to ineffective infection control strategies is also a source of the development of AMR in bacteria as well as the spread of AMR bacteria. The prevalence of CTX-M Klebsiella pneumoniae, ${ }^{27}$ Salmonella typhi and Salmonella paratyphi, ${ }^{28}$ and MRSA ${ }^{29}$ has been documented in UK hospitals. Each study has identified poor infection control measures as a contributing factor to the spread of antimicrobial resistant microorganisms. While studies have found isolates of non-resistant Pseudomonas aeruginosa from water systems in UK hospital wards ${ }^{30}$ as well as isolates of non-resistant Staphylococcus spp from various clinical instruments, ${ }^{31}$ the risk of AMR evolution still exists. High standards in infection control are crucial, especially when staff are charged with the care of critically ill patients who are most susceptible to infections from antimicrobial resistant organisms. ${ }^{32}$

In the community setting, unchecked prescribing of antimicrobial agents has been identified as a contributing factor to the spread of antimicrobial resistant bacteria. ${ }^{33}$ Due to misuse and abuse of antibiotics, the ECDC has recommended that antibiotic usage should be recorded as defined daily doses (DDD) over time. ${ }^{22}$ Supplementary data such as the number of packages used per day and details about the package content enhances knowledge regarding the antibiotic consumption. ${ }^{22}$ Support for this recommendation was evidenced by a European study which showed that the average DDD per package increased between 0.04 and 0.31 per year. ${ }^{34}$ This marked increase in antibiotic use is an indication of the potential risk of antimicrobial resistant bacteria transmission. ${ }^{35}$

Another aspect of inadequate infection control is the disposal of waste containing antibiotics. Samples of waste water and surface water from the UK environment were shown to contain multiple antibiotics such as amoxicillin, oxytetracycline and trimethoprim. ${ }^{36}$ Emerging contaminants (EC) found in water sources at sites in Oxford along the Thames river and Boxford along the River Lambourn included pharmaceuticals. ${ }^{37}$ ECs were also found in the Chalk aquifer, which provides potable water to parts of the UK. ${ }^{38}$ The presence of antibiotics in water sources is an important factor in AMR since these compounds tend to be water-soluble and remain in the environment. ${ }^{39,40}$ Improper waste disposal from farms and communities could contribute to the presence of antibiotics in UK water sources. ${ }^{41}$ The constant exposure of non-resistant bacteria to antibiotics in water sources may encourage the evolution of antimicrobial resistant bacteria.

Another important consideration is the exposure of humans to water sources that are contaminated with antimicrobial resistant bacteria. A recent study showed that samples taken from coastal waters of England and Wales had a prevalence of $1.2 \%$ of $3^{\text {rd }}$ generation cephalosporin-resistant E. coli. ${ }^{42}$ This value may be low since only one strain of resistant $E$. coli was investigated. Persons taking part in recreational activities in these areas, such as water sports, swimming and diving, had an increased risk of infection from antimicrobial resistant bacteria due to ingestion of contaminated water.

\section{Antimicrobial resistance to colistin}

Colistin, also known as polymixin E, has been considered as a critical agent against some common multidrug-resistant Gram-negative aerobic bacilli, including CPEs. The mechanism of action of colistin is to damage the integrity of the outer envelope of Gram-negative bacilli by causing instability of membrane-bound lipopolysaccharides. ${ }^{43}$ This damage allows cellular contents to escape, which results in 
apoptosis. Because of its toxic effects on the human kidney, colistin use in antimicrobial therapy was halted. ${ }^{44}$ However, the rapid emergence of CPEs had prompted the return of the usage of this drug. Overuse of colistin has now resulted in infections caused by colistin-resistant CPEs. Initially, resistance was thought to result from chromosomal mutations. Recent reports on colistin resistance in Europe, including a study published by the ECDC, ${ }^{45}$ revealed that resistance can now be mediated by the transfer of plasmids containing the colistin-resistant gene known as MCR-1. ${ }^{46-50}$

\section{Infection control strategies to curb the spread of antimicrobial resistant bacteria}

Effective infection control strategies are important in reducing the spread of antimicrobial resistant bacteria. One strategy is the implementation of policies and guidelines. The Department of Health has issued a 5 -year plan that involves policies to lessen the impact of AMR on both humans and animals. The paper identifies seven important actions needed to achieve this goal, which includes the revision of infection control practices in agriculture and human settings. ${ }^{51}$

Adherence to proper and effective animal husbandry was recommended as a way of protecting animals from infectious antimicrobial resistant bacteria., ${ }^{9,51}$ In terms of antimicrobial therapy, farmers and agricultural authorities should maintain accurate information regarding health and safety practices and antibiotic use. ${ }^{9}$ Other recommendations include a total ban of antibiotic use in prophylaxis, a ban on unregulated antibiotics in animals and discontinuation of cephalosporins and fluoroquinolones in animal antimicrobial chemotherapy. ${ }^{8}$

The 2013 edition of the NICE clinical guidelines has defined clear rules that govern infection control practices in both hospital and non-hospital environments. These include proper training of all staff, availability of items needed to carry out their duties (gloves, antiseptic agents, etc.), effective sterilisation and disinfection techniques and proper waste disposal management. ${ }^{52}$ These measures should be at the forefront of infection control since there has been an increase in public interest in CPEs in the UK. ${ }^{53}$ Decontamination, disinfection and sterilisation have been identified as excellent methods of the elimination and extermination of infectious agents. ${ }^{54}$ Another method of reducing the spread of infectious organisms is the proper use of gloves. ${ }^{55}$

A key action of the UK five-year plan is to encourage research and development in new antibiotic drug therapies. ${ }^{51}$ Due to the overuse of antibiotics in humans and animals, which was first reported by the Swann Committee (1969) and the increase of the "major public health threat" of AMR as highlighted in House of Lords' report (1998), there is an immediate need for new antibiotic drugs. ${ }^{56}$ The progress of novel drug discovery is limited by factors such as financial gain and strict regulations regarding drug trials and manufacture. ${ }^{57}$ Authorities have altered such regulations, which has revitalised the interest of large pharmaceutical companies into resuming the search for new and more effective drugs against antimicrobial resistant bacteria. ${ }^{58}$ This endeavour could also be strengthened with synergistic studies that show the mechanism(s) of combinatorial therapies..$^{59}$ Researchers are also encouraged to investigate natural-based and semi-synthetic compounds as viable alternatives. Some medicinal scientists have identified chalcones, ${ }^{60}$ which are plant-based intermediates of flavonoids, and their ferrocenyl derivatives as potential drugs since these exhibit potent antimicrobial activity. ${ }^{61-64}$

\section{Conclusion}

Infection control practices and appropriate prescribing of antibiotics are essential tools against AMR. With the overuse of antibiotics on farms and in human medicine across the UK, it is evident that AMR continues to spread. However, this increase in the prevalence of antimicrobial resistant bacteria and their resulting infections could be slowed with the implementation of effective policies for antibiotic use in animals and farms, strict decontamination and sterilisation techniques and better regulations that encourage the search for new and novel drugs.

\section{Conflicts of Interest}

The authors whose names are listed in this article certify that they have NO affiliations with or involvement in any organization or entity with any financial interest, or non-financial interest in the subject matter or materials discussed in this manuscript. No sources of funding were required for this review. 


\section{References}

1 HPA. English National Point Prevalence Survey on Healthcareassociated Infections and Antimicrobial Use, 2011: Preliminary data. Health Protection Agency, London; 2012.

2 Mitchell BG, Hall L, MacBeth D, Gardner A, Halton K. Hospital infection control units: Staffing, costs, and priorities. Am J Infect Control 2015; 43(6): 612-616. https://doi. org/10.1016/j.ajic.2015.02.016

3 Warren P. The UK's National Health Service does not meet its control standards. J Hosp Infect 2005; 59(1): 1-3. https://doi. org/10.1016/j.jhin.2004.07.017

4 Budd E. ARHAI's 5th annual report 2013 to 2014. London; 2014.

5 NICE. Infection - Prevention and control of healthcareassociated infections in primary and community care. National Institute for Health and Care Excellence, London; 2012.

6 WHO. Worldwide country situation analysis: response to antimicrobial resistance. World Health Organisation, Geneva; 2015.

7 O'Neill J. Antimicrobial Resistance : Tackling a crisis for the health and wealth of nations. The Review on Antimicrobial Resistance, London; 2014.

8 ASOA. Antimicrobial resistance - why the irresponsible use of antibiotics in agriculture must stop. The Alliance to Save Our Antibiotics, Bristol; 2014.

9 Elliott K. Antibiotics on the Farm : Agriculture's Role in Drug Resistance. CGD Policy Paper 059. Washington, DC, USA; 2015.

10 De Briyne N, Atkinson J, Borriello SP, Pokludova L. Antibiotics used most commonly to treat animals in Europe. Vet Rec 2014; 175: 325. https://doi.org/10.1136/vr.102462

11 Boulton AC, Rushton J, Wathes DC. A Study of dairy heifer rearing practices from birth to weaning and their associated costs on UK dairy farms. Open J Anim Sci 2015; 5: 185-197. https://doi.org/10.4236/ojas.2015.52021

12 Jones PJ, Marier E, Tranter RB, Wu G, Watson E, Teale CJ. Factors affecting dairy farmers' attitudes towards antimicrobial medicine usage in cattle in England and Wales. Prev Vet Med 2015; 121(1-2): 30-40. https://doi.org/10.1016/j. prevetmed.2015.05.010

13 Cornall K, Wall R. Ectoparasites of goats in the UK. Vet Parasitol 2015; 207(1-2): 176-179. https://doi.org/10.1016/j. vetpar.2014.11.005

14 Hughes L, Hermans P, Morgan K. Risk factors for the use of prescription antibiotics on UK broiler farms. I Antimicrob Chemother 2008; 61(4): 947-952. https://doi.org/10.1093/ $\mathrm{jac} / \mathrm{dkn} 017$

15 Visschers VHM, Backhans A, Collineau L, et al. Perceptions of antimicrobial usage, antimicrobial resistance and policy measures to reduce antimicrobial usage in convenient samples of Belgian, French, German, Swedish and Swiss pig farmers. Prev Vet Med 2015; 119(1-2): 10-20. https://doi. org/10.1016/j.prevetmed.2015.01.018

16 Alarcon P, Wieland B, Mateus ALP, Dewberry C. Pig farmers' perceptions, attitudes, influences and management of information in the decision-making process for disease control. Prev Vet Med 2014; 116(3): 223-242. https://doi. org/10.1016/j.prevetmed.2013.08.004

17 Cooke J, Stephens P, Ashiru-Oredope D, Johnson AP, Livermore DM, Sharland M. Antibacterial usage in English NHS hospitals as part of a national Antimicrobial Stewardship Programme. Public Health 2014; 128(8): 693-697. https://doi. org/10.1016/j.puhe.2014.06.023

18 Buchanan J, Wordsworth S, O'Connor L, et al. Management of patients with suspected infectious diarrhoea in hospitals in England. J Hosp Infect 2015; 90(3): 199-207. https://doi. org/10.1016/j.jhin.2014.12.021
19 Burnett E, Lee K, Rushmer R, Ellis M, Noble M, Davey P. Healthcare-associated infection and the patient experience: a qualitative study using patient interviews. I Hosp Infect 2010; 74(1): 42-47. https://doi.org/10.1016/j.jhin.2009.07.027

20 Shallcross LJ, Davies SC. GP antibiotic overuse and microbial resistance. Br J Gen Pract 2015; 65(631): 61-62. https://doi. org/10.3399/bjgp15X683413

21 Tang SS, Apisarnthanarak A, Hsu LY. Mechanisms of $\beta$-lactam antimicrobial resistance and epidemiology of major community- and healthcare-associated multidrug-resistant bacteria. Adv Drug Deliv Rev 2014; 78: 3-13. https://doi. org/10.1016/j.addr.2014.08.003

22 Roca I, Akova M, Baquero F, et al. The global threat of antimicrobial resistance: Science for intervention. New Microbes New Infect 2015; 6: 22-29. https://doi.org/10.1016/j. nmni.2015.02.007

23 Woolhouse M, Ward M, van Bunnik B, Farrar J. Antimicrobial resistance in humans, livestock and the wider environment. Philos Trans R Soc Lond B Biol Sci 2015; 370(1670): 20140083. https://doi.org/10.1098/rstb.2014.0083

24 Randall L, Heinrich K, Horton R, et al. Detection of antibiotic residues and association of cefquinome residues with the occurrence of Extended-Spectrum $\beta$-Lactamase (ESBL)producing bacteria in waste milk samples from dairy farms in England and Wales in 2011. Res Vet Sci 2014; 96(1): 15-24. https://doi.org/10.1016/j.rvsc.2013.10.009

25 Snow LC, Warner RG, Cheney T, et al. Risk factors associated with extended spectrum beta-lactamase Escherichia coli (CTX-M) on dairy farms in North West England and North Wales. Prev Vet Med 2012; 106(3-4): 225-234. https://doi. org/10.1016/j.prevetmed.2012.03.009

26 Moore JE, Huang J, Yu P, et al. High diversity of bacterial pathogens and antibiotic resistance in salmonid fish farm pond water as determined by molecular identification employing $16 \mathrm{~S}$ rDNA PCR, gene sequencing and total antibiotic susceptibility techniques. Ecotoxicol Environ Saf 2014; 108: 281-286. https://doi.org/10.1016/j.ecoenv.2014.05.022

27 Lob SH, Biedenbach DJ, Badal RE, Kazmierczak KM, Sahm DF. Antimicrobial resistance and resistance mechanisms of Enterobacteriaceae in ICU and non-ICU wards in Europe and North America: SMART 2011-2013. J Glob Antimicrob Resist 2015; 3(3): 190-197. https://doi.org/10.1016/j. jgar.2015.05.005

28 Dave J, Sefton A, de Pinna E, et al. Trends in antibiotic susceptibility of enteric fever isolates in East London. Travel Med Infect Dis 2015; 13(3): 230-234. https://doi. org/10.1016/j.tmaid.2015.04.001

29 Newitt S, Myles PR, Birkin JA, et al. Impact of infection control interventions on rates of Staphylococcus aureus bacteraemia in National Health Service acute hospitals, East Midlands, UK, using interrupted time-series analysis. J Hosp Infect 2015; 90(1): 28-37. https://doi.org/10.1016/j.jhin.2014.12.016

30 Loveday H, Wilson JA, Kerr K, Pitchers R, Walker JT, Browne J. Association between healthcare water systems and Pseudomonas aeruginosa infections: a rapid systematic review. J Hosp Infect 2014; 86(1): 7-15. https://doi.org/10.1016/j. jhin.2013.09.010

31 Mahida N, Levi K, Kearns A, Snape S, Moppett I. Investigating the impact of clinical anaesthetic practice on bacterial contamination of intravenous fluids and drugs. I Hosp Infect 2015; 90(1): 70-74. https://doi.org/10.1016/j. jhin.2014.11.024

32 Bauchmuller K, Faulds MC. Care of the critically ill patient. Surg 2015; 33(4): 165-171. https://doi.org/10.1016/j. mpsur.2015.01.009

33 Spellberg B, Guidos R, Gilbert D, et al. The epidemic 
of antibiotic-resistant infections: a call to action for the medical community from the Infectious Diseases Society of America. Clin Infect Dis 2008; 46(2): 155-164. https://doi. org/10.1086/524891

34 Bruyndonckx R, Hens N, Aerts M, Goossens H, Molenberghs $\mathrm{G}$, Coenen S. Measuring trends of outpatient antibiotic use in Europe: Jointly modelling longitudinal data in defined daily doses and packages. J Antimicrob Chemother 2014; 69(7): 1981-1986. https://doi.org/10.1093/jac/dku063

35 Busfield J. Assessing the overuse of medicines. Soc Sci Med 2015; 131: 199-206. https://doi.org/10.1016/j. socscimed.2014.10.061

36 Petrie B, Barden R, Kasprzyk-Hordern B. A review on emerging contaminants in wastewaters and the environment: Current knowledge, understudied areas and recommendations for future monitoring. Water Res 2014; 72(0): 3-27.

37 Stuart ME, Lapworth DJ, Thomas J, Edwards L. Fingerprinting groundwater pollution in catchments with contrasting contaminant sources using microorganic compounds. Sci Total Environ 2014; 468-469: 564-577. https://doi.org/10.1016/j. scitotenv.2013.08.042

38 Lapworth DJ, Baran N, Stuart ME, Manamsa K, Talbot J. Persistent and emerging micro-organic contaminants in Chalk groundwater of England and France. Environ Pollut 2015; 203: 214-225. https://doi.org/10.1016/j.envpol.2015.02.030

39 Zhang D, Gersberg RM, Ng WJ, Tan SK. Removal of pharmaceuticals and personal care products in aquatic plantbased systems: A review. Environ Pollut 2014; 184(2014): 620 639. https://doi.org/10.1016/j.envpol.2013.09.009

40 Fernandes JP, Almeida CMR, Pereira AC, et al. Microbial community dynamics associated with veterinary antibiotics removal in constructed wetlands microcosms. Bioresour Technol 2015; 182: 26-33. https://doi.org/10.1016/j. biortech.2015.01.096

41 Stuart M, Lapworth D, Crane E, Hart A. Review of risk from potential emerging contaminants in UK groundwater. Sci Total Environ 2012; 416: 1-21. https://doi.org/10.1016/j. scitotenv.2011.11.072

42 Leonard AFC, Zhang L, Balfour AJ, Garside R, Gaze WH. Human recreational exposure to antibiotic resistant bacteria in coastal bathing waters. Environ Int 2015; 82: 92-100. https:// doi.org/10.1016/j.envint.2015.02.013

43 Newton BA. The properties and mode of action of the polymixins. Bact Rev 1956; 20: 14-27.

44 Falagas ME, Kasiakou SK. Toxicity of polymyxins: a systematic review of the evidence from old and recent studies. Crit Care 2006; 10(1): 1-13. https://doi.org/10.1186/cc3910

45 European Centre for Disease Prevention and Control (ECDC). Plasmid-mediated colistin resistance in Enterobacteriaceae. Stockholm; 2016.

46 Liu YY, Wang Y, Walsh TR, et al. Emergence of plasmidmediated colistin resistance mechanism MCR-1 in animals and human beings in China: A microbiological and molecular biological study. Lancet Infect Dis 2016; 16: 161-168. https:// doi.org/10.1016/S1473-3099(15)00424-7

47 Doumith M, Godbole G, Ashton P, et al. Detection of the plasmid-mediated mcr-1 gene conferring colistin resistance in human and food isolates of Salmonella enterica and Escherichia coli in England and Wales. I Antimicrob Chemother 2016; 71(8): 2300-2305. https://doi.org/10.1093/jac/dkw093

48 Schwarz S, Johnson AP. Transferable resistance to colistin: A new but old threat. I Antimicrob Chemother 2016; 71(8): 2066-2070. https://doi.org/10.1093/jac/dkw274

49 Day $M$, Doumith $M$, Jenkins $C$, et al. Antimicrobial resistance in Shiga toxin-producing Escherichia coli serogroups O157 and $\mathrm{O} 26$ isolated from human cases of diarrhoeal disease in England, 2015. J Antimicrob Chemother 2016; 72: 145-152. https://doi.org/10.1093/jac/dkw371

50 Findlay J, Hopkins KL, Alvarez-buylla A, et al. Characterization of carbapenemase-producing Enterobacteriaceae in the West Midlands region of England: 2007-14. J Antimicrob Chemother 2017; 10: 1-9. https://doi.org/10.1093/jac/dkw560

51 DOH. UK Five Year Antimicrobial Resistance Strategy 2013 to 2018. Department of Health, London; 2013.

52 Loveday HP, Wilson JA, Pratt RJ, et al. epic3: national evidencebased guidelines for preventing healthcare-associated infections in NHS hospitals in England. The Journal of Hospital Infection 2014; 86(1): S1-S70. https://doi.org/10.1016/S01956701(13)60012-2

53 Otter JA. What's trending in the infection prevention and control literature? From HIS 2012 to HIS 2014, and beyond. I Hosp Infect 2015; 89(4): 229-236. https://doi.org/10.1016/j. jhin.2015.02.004

54 de Zoysa H, Morecroft E. Cleaning, disinfection and sterilization of equipment. Anaesth Intensive Care Med 2007; 8(11): 453-456. https://doi.org/10.1016/j.mpaic.2007.09.001

55 Loveday HP, Lynam S, Singleton J, Wilson J. Clinical glove use: Healthcare workers' actions and perceptions. I Hosp Infect 2014; 86(2): 110-116. https://doi.org/10.1016/j. jhin.2013.11.003

56 Wise R. The urgent need for new antibacterial agents. J Antimicrob Chemother 2011; 66(9): 1939-1940. https://doi. org/10.1093/jac/dkr261

57 Livermore DM. Discovery research: the scientific challenge of finding new antibiotics. J Antimicrob Chemother 2011; 66(9): 1941-1944. https://doi.org/10.1093/jac/dkr262

58 Bax R, Green S. Antibiotics: the changing regulatory and pharmaceutical industry paradigm. I Antimicrob Chemother 2015; 70(5): 1281-1284. https://doi.org/10.1093/jac/dku572

59 Bollenbach T. Antimicrobial interactions: mechanisms and implications for drug discovery and resistance evolution. Curr Opin Microbiol 2015; 27: 1-9. https://doi.org/10.1016/j. mib.2015.05.008

60 Harborne JB, Williams CA. Advances in flavonoid research since 1992. Phytochemistry 2000; 55(6): 481-504. https://doi. org/10.1016/S0031-9422(00)00235-1

61 Pejović A, Damljanović I, Stevanović D, et al. Antimicrobial ferrocene containing quinolinones: Synthesis, spectral, electrochemical and structural characterization of 2-ferrocenyl-2,3-dihydroquinolin-4(1H)-one and its 6-chloro and 6-bromo derivatives. Polyhedron 2012; 31(1): 789-795. https://doi.org/10.1016/j.poly.2011.11.006

62 Kowalski K, Koceva-Chy A, Szczupak L, et al. Ferrocenylvinylflavones: Synthesis, structure, anticancer and antibacterial activity studies. / Organomet Chem 2013; 741-742(1): 153161. https://doi.org/10.1016/j.jorganchem.2013.05.009

63 Prasath R, Bhavana P, Ng SW, Tiekink ERT. The facile and efficient ultrasound-assisted synthesis of new quinolineappended ferrocenyl chalcones and their properties. I Organomet Chem 2013; 726: 62-70. https://doi.org/10.1016/j. jorganchem.2012.12.022

64 Ahmed N, Konduru NK, Owais M. Design, synthesis and antimicrobial activities of novel ferrocenyl and organic chalcone based sulfones and bis-sulfones. Arab / Chem 2015. https://doi.org/10.1016/j.arabjc.2014.12.008 